\title{
KNOWLEDGE, ATTITUDE AND PREVENTIVE PRACTICES ABOUT DENGUE FEVER AMONG NURSING STUDENT OF TERTIARY CARE HOSPITAL
}

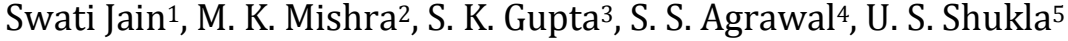

\section{HOW TO CITE THIS ARTICLE:}

Swati Jain, M. K. Mishra, S. K. Gupta, S. S. Agrawal, U. S. Shukla. "Knowledge, Attitude and Preventive Practices about Dengue Fever among Nursing Student of Tertiary Care Hospital". Journal of Evolution of Medical and Dental Sciences 2014; Vol. 3, Issue 06, February 10; Page: 1481-1488, DOI: 10.14260/jemds/2014/2011

ABSTRACT: Dengue fever (DF) is increasingly recognized as one of the world's major vector borne diseases and causes significant morbidity \& mortality in most tropical \& subtropical countries of the world \& had become the most common arboviral diseases of human. Dengue fever is endemic in most part of India \& continues to be a public health concern. Dengue vector, human knowledge \& human behavior each have been reported to play an important role in the transmission of the diseases. OBJECTIVES: 1 . To determine the level of knowledge, attitude \& practices regarding Dengue fever among nursing student. 2. To study the relationship of level of knowledge $\&$ attitude with preventive practices for dengue fever. METHOD \& MATERIAL: A cross sectional study was carried out in nursing student of tertiary care hospital during September to October2012. A prestructured \& selfadministered questionnaire was used to collect data regarding dengue fever knowledge, attitude \& practices from nursing students. STATISTICAL ANALYSIS: Data was analyzed using SPSS version 20 statistical software. Appropriate statistical test was applied to calculate P-value. RESULT: Almost all the participants have heard of DF (94\%), the media being the most quoted source of information. Nearly $80.6 \%$ participants were aware transmission of Dengue Fever is by mosquito bite. Practices based upon preventive measures were found to be predominantly focused towards prevention of mosquito bites rather than elimination of breeding places. CONCLUSION: Although the knowledge regarding DF \& mosquito control measure was quite high among the nursing student but this knowledge was not put into practice.

KEYWORDS: Dengue fever, Knowledge, Attitude, Nursing student, Tertiary care hospital.

INTRODUCTION: Dengue fever (DF) is increasingly recognized as one of the world's major vector borne diseases. Dengue is prevalent in tropical and sub-tropical climates worldwide, mostly in urban and semi-urban areas. ${ }^{1}$ The incidence of dengue has grown dramatically around the world in recent decades. Over 2.5 billion people - over $40 \%$ of the world's population - are now at risk from dengue. WHO currently estimates there may be 50-100 million dengue infections worldwide every year. ${ }^{1}$

Before 1970, only nine countries had experienced severe dengue epidemics. The disease is now endemic in more than 100 countries in Africa, the Americas, the Eastern Mediterranean, Southeast Asia and the Western Pacific. The American, South-east Asia and the Western Pacific regions are the most seriously affected.1Dengue fever is endemic in India \& continues to be a public health concern. Major epidemics have been reported from Delhi, capital of India in the years1967, 1970, $1982,1996,2003,2006,2010.2-3$

Dengue, a vector borne disease, has hit all major cities of the country, with the total number of cases by Nov 2012 reaching 37,070 including 227 deaths - a sharp increase from 18,860 cases and 169 deaths in 2011.4 
Dengue fever is caused by a mosquito-borne human viral pathogen that belongs to the genus Flavivirus of the family Flaviviridae (single-strand, non-segmented RNA viruses).There are four dengue serotypes (DEN-1, DEN-2, DEN-3and DEN-4). Dengue is transmitted to humans by two species of Aedes mosquitoes namely, Aedes aegypti (principal vector) and Aedes albopictus. Although infection with one dengue serotype confers lifetime immunity against re-infection by the same serotype, there is no evidence of cross immunity. ${ }^{5} \mathrm{~A}$ wide clinical spectrum has been classified by the World Health Organization ${ }^{6}$ and it is possible for an individual to be infected with DF several times during his life time.

In the absence of a vaccine or specific antiviral to treat DF, vector control is one of the most important preventive measures in combating dengue. The recurrence of DF each year and the rising number of cases with each epidemic suggest that vector control efforts are probably not carried out properly and need to be improved. Dengue vector, human knowledge \& human behavior each have been reported to play an important role in the transmission of the diseases. Considering the magnitude of the problem the present study was undertaken to assess the knowledge \& attitude of the nursing students regarding dengue and the preventive practices undertaken by them \& to determine the relationship of dengue fever prevention practices with level of knowledge $\&$ attitude.

\section{METHOD \& MATERIAL:}

Study setting: A cross sectional study was planned \& carried out among nursing students of tertiary care hospital during September to October2012. A prestructured \& self-administered questionnaire was prepared, validated \& used to collect information regarding knowledge, attitude \& practices regarding dengue fever from nursing students. The study population included all the nursing students of class $1^{\text {st }}, 2^{\text {nd }}, 3^{\text {rd }}, 4^{\text {th }}$ year who were present at the time of study. Total two hundred \& one nursing students were included in the study.

Study instrument: A prestructured \& self-administered questionnaire was used to collect data regarding dengue fever knowledge, attitude \& practices from nursing students.. Data were collected from 201 respondents.

Data analysis: Data was analyzed using SPSS version 20 statistical software. Responses to questions were coded such that correct answers scored one and incorrect answers scored zero. These scores were added to arrive at a single value out of a possible total score of 9 for knowledge, 11 for attitude and 8 for practice. Respondents were considered to have good knowledge if they correctly answered more than $66.6 \%$ of the questions similarly respondents were regarded as having positive attitude towards prevention of dengue if they scored more than $50 \%$ of the questions. Participants were deemed to have good preventive practices if they answered more than $50 \%$ of the questions correctly.

RESULT: The socio-demographic characteristics of respondent are given in Table-1. The table shows that, among 201 nursing students, 168(83.6\%) were female and 33 (16.4\%) were male. About 52.2\% of them were in age group 20-25 years.

The study found that almost all (94\%) had heard of dengue fever and many students ie37.8\% derived this information from TV followed by print media (23.4\%) whereas only $7 \%$ student had 
information from radio broadcasts. Apart from media another source of information was nursing teachers $(16.4 \%)$, doctor (12.4\%), family and friends (3\%). (Table - 2) Majority of respondents had obtained information through multiple sources.

Overall $80.6 \%$ were aware that dengue spreads by mosquito bite. However, 9.5\% respondents reported dengue spreads by drinking dirty water. (Table-3) Regarding species of mosquito (Aedes) which spread dengue, only less than half of the respondents (44.3\%) could answer correctly aedes mosquito. $20.9 \%$ of the respondents reported main breeding place of dengue mosquito is coolers \& tyres whereas only $16.9 \%$ reported that mosquito breed on stagnant water. (Table-3). Only 15.9\% respondents correctly reported that Aedes mosquito bites during day time. Around $43.8 \%$ respondents were aware of fever with rash as the presenting symptom whereas $30.3 \%$ were reported that only fever is the presenting symptom. Headache was considered as a symptom by only $8 \%$ of respondents whereas other symptoms like vomiting and bleeding from nose were reported by $9.5 \%$ and $3.5 \%$ respectively. (Table-3)

The majority of the participants (52.2\%) preferred to take the patient to a doctor. Regarding medications paracetamol (32.8\%) was drug of choice, followed by boiled coriander(14.4\%) and aspirin (9\%). As for as dengue vaccination is concern most of the respondents (42.3\%) thinks that dengue vaccine is available.

Based on cumulative scoring for the attitude it has brought that majority of the respondent $(68.7 \%)$ have perceived that illness is serious, needs treatment and hospitalization and have positive attitude regarding responsibility of controlling mosquito breeding.

When asked about available measures to prevent man mosquito's contact only $25.4 \%$ respondents were aware that screening of windows \& ventilators reduced contact with mosquitoes. Whereas $30.3 \%$ cited use of antimosquito sprays and burning of Neem leaves $(10.9 \%)$ as a means of destroying mosquitoes while (24.9\%) felt that regular cleaning and covering water storage tank reduce mosquito breeding. Regarding personal protection against mosquito bite, mosquito mats/liquid vaporizers were used by $15.4 \%$ respondent while $3.5 \%$ respondent prefers covering their body with cloth. Many respondents (43.8\%) mentioned draining or removal of stagnant water is an important practice for prevention of mosquito breeding. (Table-4)

Amongst those who possessed coolers, cleaning and use of oil was asked. Adequate cleaning was defined as cleaning of the coolers once a week. It was found that only $26.9 \%$ of respondents adequately cleaned their coolers and $24.4 \%$ used oil. About $62(30.9 \%)$ nursing students reported that authorities (health officers \& administration) is responsible for taking steps to prevent mosquito breeding whereas only 29.4\%) respondents believed that their participation in community campaigns will be valuable in controlling mosquito breeding site.

Based on the scoring system described in the methodology knowledge, attitude \& practice of each respondent was assessed, $57.2 \%$ had satisfactory knowledge on the symptoms, management \& transmission of Dengue. $68.7 \%$ of the respondents demonstrated satisfactory attitudes \& only17.9\% claimed to have used good practices towards dengue. (Table-5)

Knowledge regarding dengue fever had significant association with attitude $(\mathrm{P}<0.05)$. The nursing students with good knowledge had more positive attitude regarding perception of severity of illness, need for treatment \& their responsibility of controlling mosquito breeding site. A significant statistical association was found between preventive practices and knowledge about dengue fever spread \& transmission. $(\mathrm{P}<0.05)$. 
DISCUSSION: This study sought to assess nursing student knowledge, attitude and practices related to dengue infection. Our study revealed that almost all respondents (94\%) had heard about Dengue .Findings are similar to study conducted in OPD of AIIMS, New Delhi in which $96.3 \%$ respondent were reported to be aware of dengue ${ }^{7}$. However similar studies conducted in Brazil ${ }^{8} \&$ Thailand ${ }^{9}$ responses are $78 \%$ \& 67\% respectively which is lower from our study. The possible reasons for better awareness could be repeated exposure of nursing student to health education messages on dengue and other mosquito- borne diseases by nursing teachers. In the present study, television emerges as most important source of information (37.8\%). This is similar to a study from North India \& south Delhi 7,10. This emphasizes upon the fact that mass media like television is a very important source of information and this can be further used to disseminate more awareness regarding dengue. Mosquito bite was cited as a cause of dengue by $80.6 \%$ respondents and results are in consonance with studies conducted by Itrat A et al in a tertiary care hospital in Karachi 11 and Chinnakali et al in AIIMS New Delhi. ${ }^{7}$ There was misconceptions amongst 9.5\% respondents that dirty drinking water can cause dengue $\& 3.5 \%$ thought that houseflies spread dengue.

These observations demand the need to educate the nursing students on causative aspects and breeding sites of dengue so as to help them to understand and practice the preventive measure. The Aedes aegypti mosquito is known to bite mostly during several hours after dawn and before dusk. ${ }^{12}$ Interestingly, only about $15.9 \%$ of respondents were aware of this unique behavior of the vector. Bridging this gap in knowledge is essential in the design of programs to educate nursing students on personal protection against mosquitoes. It was found that $43.7 \%$ respondents could enumerate fever with rash as the presenting symptom while $30.3 \%$ of respondents mention only fever as the presenting symptom.

This observation differed from a study conducted by Matta $S$ et al where 61.8\% were aware of only fever as the presenting symptom ${ }^{13}$. Also study done in East Delhi by Gupta P et al observed that fever was commonest symptom of the disease known to $83 \%$ of the respondents ${ }^{14}$. This difference may be due to regular exposure of nursing students to health professionals including doctors, nursing teacher as well as patients. Knowledge of management strategies for the disease was high among respondent. Mosquito mats, coil and repellent cream were used during night time. This highlights the existing gap in the knowledge with respect to the biting habits of Aedes mosquito. Measures aimed at preventing water stagnation, which serves as local breeding sites were popular techniques (43.8\%) in use. This is in accordance with studies done in Thailand which reported a significant reduction of dengue vectors and dengue hemorrhagic fever cases in areas having clean-up campaigns before and during rainy seasons ${ }^{15}$.

Although the nursing students were aware of good practices regarding the elimination of mosquito breeding sites only a minor percentage would inform the relevant health authorities of unattended breeding sites in their community. Knowledge application gap was noticed amongst the respondents. It was observed that preventive measures were less as compared to knowledge regarding application of them. Similar gap between knowledge and preventive practices was also observed by Itrat $A$ et al $^{11}$ in their study.

Our findings must be interpreted in the light of several potential limitations. The most apparent of which may be the fact that a cross sectional survey assesses relationships based on one point in time. As this was a self-administered questionnaire it is possible that the participants might have provided socially desirable responses especially regarding practices. 
CONCLUSION: Among nursing student of tertiary care hospital, the main source of information about Dengue fever was obtained from the mainstream media including both newsprint \& television. The low prevalence of sufficient knowledge, based on an overall knowledge score on dengue, was evident among nursing students. However, isolated knowledge on symptoms and prevention may be considered somewhat adequate. The known preventive measures mainly focused on protection from mosquito bite. In spite of our study limitations our findings highlight the need for further information, education and communication programs in the community.

RECOMMENDATION: Educational interventions to target community, colleges and schools are urgently needed. Raising the knowledge levels of nursing students, who may become future care provider at various level of health system, is important. Health education and Behaviors change communication can play a major role in informing and encouraging citizens to be responsible, and to participate in preventing and controlling DF. School \& college based education is vital and compliment community outreach education. This education will help transfer of knowledge from classrooms to homes \& in establishing sound DF preventive and control practices for society as a whole.

\section{REFERENCES:}

1. WHO, Geneva. Dengue and dengue haemorrhagic fever. Geneva: WHO; 2009 [last cited on29 DEC 2013]; Available from:http://www.who.int/mediacentre/factsheets/fs117/en/.

2. Balaya S, Paul SD, D'Lima LV, Pavri KM. Investigations on an outbreak of dengue in Delhi in 1967. Indian J Med Res 1969; 57: 767-74.

3. Annual Report 2004-05. New Delhi: Ministry of Health \&Family Welfare (Govt. of India) 2005; p. $2 \& 38$.

4. Times of India, Dated 24 Nov, 2012: 4-5 pages.

5. CDC, Centers for Disease Control and Prevention. Dengue fever. Colorado; 2008 [cited on 29DEC2012]; Available from: http://www.cdc.gov/ncidod/dvbid/dengue/.

6. WHO. Prevention and control of dengue and dengue haemorrhagic fever: comprehensive guidelines. WHO Regional Publication, 1999.

7. Chinnakali P, Gurnani N, Upadhyay RP, Parmar K, Suri TM, Yadav K. High level of awareness but poor practices regarding dengue fever control : a cross-sectional study from North India. North American Journal of Medical Sciences 2012; 4:278-282.

8. Degallier N, Vilarinhos PT, deCarvalho MS, Knox MB, Caetano J Jr. People's knowledge and practice about dengue, its vectors, and control means in Brasilia (DF), Brazil: its relevance with entomological factors. J Am Mosq Contr Assoc 2000; 16: 114-23.

9. Swaddiwudhipong W, Lerdlukanavonge P, Khumklam P, Koonchote S, Nguntra P, Chaovakiratipong C. A survey of knowledge, attitude and practice of the prevention of dengue hemorrhagic fever in an urban community of Thailand. Southeast Asian J Trop Med Pub Hlth 1992; 23: 207-11.

10. Acharya A, Goswami K, Srinath S, Goswami A. Awareness about dengue syndrome and related preventive practices amongst residents of an urban resettlement colony of south Delhi. J Vect Borne Dis 2005; 42: 122-7. 
11. Itrat A, Khan A, Javaid S, Kamal M, Khan H, Javed S, Kalia S, Khan AH, Sethi MI, Jehan I. Knowledge , Awareness and Practices Regarding Dengue Fever among the Adult Population of Dengue Hit Cosmopolitan. PLoS ONE. 2008; 3:2620-2626.

12. CDC, Centers for Disease Control and Prevention. Travel yellow book. In: CDC, editor. CDC Health Information for International Travel 2008. Atlanta, Georgia; 2008.

13. Matta S, Bhalla S, Singh D, Rasania SK, Singh S. Knowledge, Attitude and Practice(KAP) on Dengue fever: A Hospital Based Study. Indian Journal of Community Medicine. 2006; 31:185186.

14. Gupta P, Kumar P, Aggarwal OP. Knowledge, attitude and practices related to dengue in rural and slum areas of Delhi after the dengue epidemic of 1996. J Commun Dis. 1998; 30:107-12.

15. Van Benthem BH, Khantikul N, Panart K, Kessels PJ, Somboon P, et al. (2002) Knowledge and use of prevention measures related to dengue in northern Thailand. Trop Med Int Health 7: 993-100.

\begin{tabular}{|l|c|c|}
\hline Distribution of respondents & Frequency & Percentage \\
\hline Age distribution (yrs.) & & \\
15-20 & 90 & $43.90 \%$ \\
$20-25$ & 105 & $52.24 \%$ \\
$25-30$ & 06 & $2.92 \%$ \\
Gender distribution & 33 & $16.4 \%$ \\
Male & 168 & $83.6 \%$ \\
Female & 42 & $20.9 \%$ \\
Class & 51 & $25.4 \%$ \\
1st year & 82 & $40.8 \%$ \\
2nd year & 26 & $12.9 \%$ \\
3rd year & 144 & $71.6 \%$ \\
4th year & 07 & $3.4 \%$ \\
Religion & 50 & $24.4 \%$ \\
Hindu & \\
Muslim & & \\
Christian & & \\
TABLE-1: Distribution of respondents according to \\
their socio-demographic characteristics \\
\hline \multicolumn{2}{|c}{}
\end{tabular}

\begin{tabular}{|l|c|c|}
\hline Source of information & Frequency & Percentage \\
\hline Radio & 14 & $7.0 \%$ \\
\hline Television & 76 & $37.8 \%$ \\
\hline Newspaper & 47 & $23.4 \%$ \\
\hline Doctor & 25 & $12.4 \%$ \\
\hline Fellow Nursing Student & 33 & $16.4 \%$ \\
\hline Friends & 6 & $3.0 \%$ \\
\hline Total & $201 \%$ & $100.0 \%$ \\
\hline
\end{tabular}

Table-2: Distribution of respondent according to their Source of information about dengue 


\begin{tabular}{|l|c|c|}
\hline Distribution of respondents & Frequency & Percentage \\
\hline Causes of dengue & 162 & $80.6 \%$ \\
Mosquito bite & 19 & $9.5 \%$ \\
Dirty drinking water & 2 & $1.0 \%$ \\
Contaminated food & 3 & $1.5 \%$ \\
Eating raw vegetables & 8 & $4.0 \%$ \\
Polluted air & 7 & $3.5 \%$ \\
Houseflies & & \\
\hline Breeding sites of dengue & 10 & \\
mosquito & 42 & $20.9 \%$ \\
Coolers & 37 & $18.4 \%$ \\
Coolers \& tyres & 10 & $5 \%$ \\
Coolers \& tyres \& flower pots & 23 & $11.4 \%$ \\
Burrows and pit & 45 & $22.4 \%$ \\
Vessels / containers & 34 & $16.9 \%$ \\
Dirty surrounding & & \\
Stagnant water & 61 & $30.3 \%$ \\
\hline Symptom of dengue & 88 & $43.7 \%$ \\
Fever only & 19 & $9.5 \%$ \\
Fever with rash & 16 & $8 \%$ \\
Vomiting & 10 & $5 \%$ \\
Headache & 7 & $3.5 \%$ \\
Abdominal pain & & \\
Bleeding from nose & & \\
\hline \multicolumn{1}{|c|}{ TABLE-3: Distribution of respondents } \\
\hline
\end{tabular}

\begin{tabular}{|l|c|c|}
\hline \multicolumn{1}{|c|}{ Preventive Practices* } & Frequency & Percentage \\
\hline Use of anti-mosquito spray & 61 & $30.3 \%$ \\
Mosquito coil/mat/Liquid vaporizer & 31 & $15.4 \%$ \\
Mosquito repellent cream & 114 & $56.7 \%$ \\
Covering body with cloth & 7 & $3.5 \%$ \\
Mosquito Net & 49 & $24.4 \%$ \\
Cleaning \& covering of water storage tank & 50 & $24.9 \%$ \\
Draining of stagnant water & 88 & $43.8 \%$ \\
Window \& door screen & 55 & $25.4 \%$ \\
Burning of Neem leaves & 22 & $10.9 \%$ \\
Use of electrocuter & 5 & $2.5 \%$ \\
\hline \multicolumn{2}{|c|}{ Table-4: Common preventive practices against Dengue }
\end{tabular}

*Multiple responses 


\section{ORIGINAL ARTICLE}

\begin{tabular}{|l|c|c|c|}
\hline Score & Knowledge & Attitude & Practices \\
\hline Satisfactory & 57.2 & 68.7 & 17.9 \\
\hline Unsatisfactory & 42.8 & 31.3 & 82.1 \\
\hline \multicolumn{4}{|l|}{ Table-5: Percentage of individual with satisfactory and } \\
unsatisfactory score in knowledge, attitude \& practices
\end{tabular}

\section{AUTHORS:}

1. Swati Jain

2. M. K. Mishra

3. S. K. Gupta

4. S. S. Agrawal

5. U. S. Shukla

\section{PARTICULARS OF CONTRIBUTORS:}

1. Post Graduate Student, Department of Community Medicine, Peoples College of Medical Sciences \& Research Center, Bhopal (M.P.)

2. Professor, Department of Community Medicine, Peoples College of Medical Sciences \& Research Center, Bhopal (M.P.)

3. Associate Professor, Department of Community Medicine, Peoples College of Medical Sciences \& Research Center, Bhopal (M.P.)
4. Professor, Department of Community Medicine, Peoples College of Medical Sciences \& Research Center, Bhopal (M.P.)

5. Assistant Lecturer, Department of Community Medicine, Peoples College of Medical Sciences \& Research Center, Bhopal (M.P.)

\section{NAME ADDRESS EMAIL ID OF THE CORRESPONDING AUTHOR:}

Dr. Swati Jain,

H.No. 236, Ecogreen Park, Ayodhya Bypass Road,

Bhopal (M.P.)

E-mail: sjain_4012006@yahoo.co.in

Date of Submission: 21/01/2014.

Date of Peer Review: 22/01/2014.

Date of Acceptance: 28/01/2014.

Date of Publishing: 06/02/2014. 